\title{
The thermodynamic method applied to hydraulic transmissions
}

\author{
ARNE KJØLLE \\ The University of Trondheim \\ The Norwegian Institute of Technology \\ Division of Hydro- and Gas Dynamics \\ Alfred Getz vei 4, 7034 Trondheim, Norway
}

\begin{abstract}
Two hydraulic transmissions are tested for determination of the efficiency by two methods, the basic one by hydraulic measurements and the other by thermodynamic measurements. The hydraulic method is giving the total efficiency of the transmission on the base of hydraulic power input to the motor and hydraulic power output from the pump. By the thermodynamic method the efficiency is determined for each one of the units, the motor and the pump. The results from these tests show an agreement between these two methods within $2-3 \%$ when temperature difference $\Delta t$ between the oil and the environment is approximately zero. A model function is suggested for reducing the deviation $\Delta \eta$ between the two methods for correcting the thermodynamic evaluations to agree with the hydraulic evaluations of the efficiency.
\end{abstract}

\section{INTRODUCTION}

The applicability of the thermodynamic method for the determination of the efficiency of hydraulic pumps and motors has been studied by several research approaches [1], [2], [3], [4], experimentally as well as theoretically. However, the thermodynamic method has still not been brought to the stage of practical use on such power units. It is still the fact that too few research results have appeared to state whether the reliability of the thermodynamic method is consistent or not.

The tests to be reported in the following comprise supplementary tests of those described in [3] and another series of tests on a different hydraulic transmission. The purpose of these tests is to accumulate test data which increase the knowledge of the limits of reliability and applicability of the thermodynamic method on hydraulic units.

\section{TEST RIG AND INSTRUMENTATION}

Experiments were carried out on two test stands. Their principal build up is shown on fig. 1.

The first one consisted of a gear pump driven by a vane motor, both having a fixed displacement, which for the pump is $V_{P}=17 \mathrm{~cm}^{3}$ and the motor $V_{M}=51 \mathrm{~cm}^{3}$ per rev.. The energy flow to the motor was supplied from a separate power pack. 


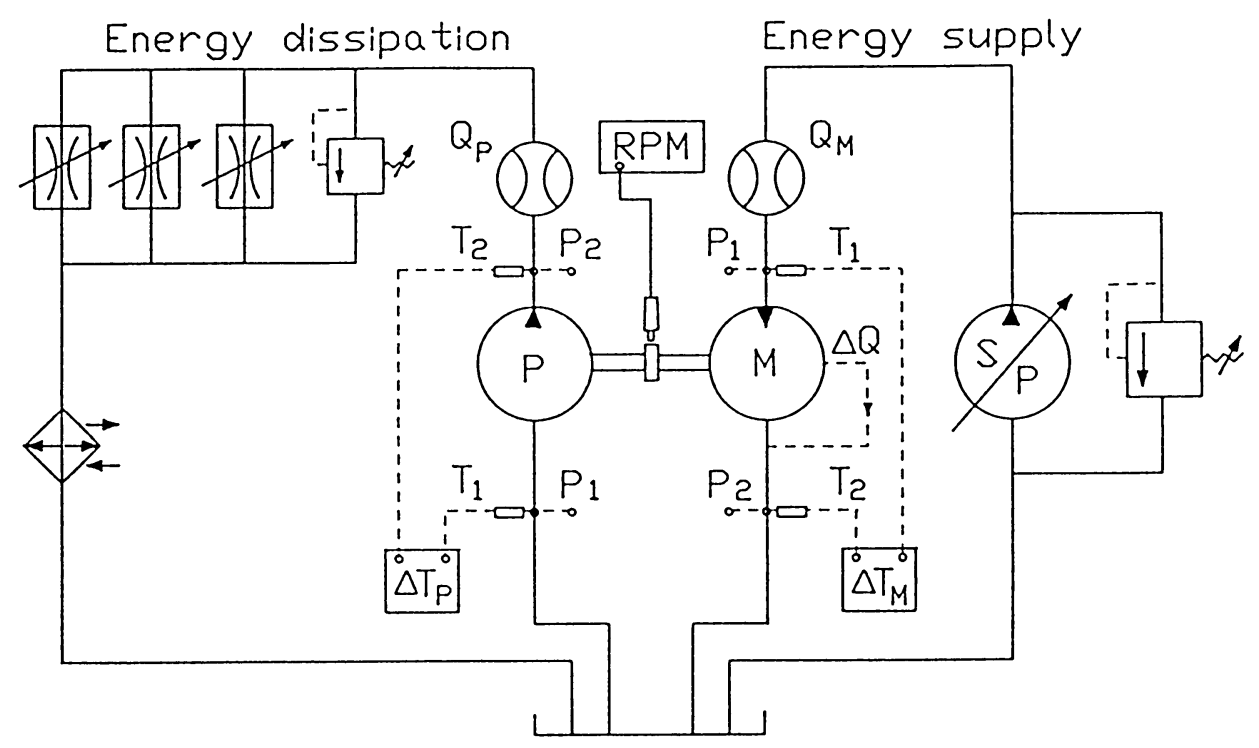

Figure 1. Hydraulic transmission

The second test stand was built up principally as the first one. The units were: A Volvo piston motor with fixed displacement $\mathrm{V}_{\mathrm{M}}=19$ $\mathrm{cm}^{3}$ and a Hydreco/Hamworthy gear pump with displacement $V_{P}=70 \mathrm{~cm}^{3}$ per rev.. The energy flow to the motor was supplied from the central pump unit in the laboratory.

The temperature sensing was arranged in the same way for the pump and motor respectively. In the pipeline circuit of the pump and the corresponding circuit of the motor, fig. 1, pockets were arranged one at the inlet and one at the outlet of each unit for the insertion of temperature sensors which are shown on fig. 2 . These pockets were made to fit the sensor with a small tolerance. For keeping a consistent contact between the sensor and the pocket wall, the narrow clearance was filled with silicone oil.

The temperature measurements were carried out with two bridges of same type and manufacture: SYSTEMTEKNIK, Model S1220, and temperature sensors: Mathey ELECTRONICS, Thermafilm "PLUS" 100 PA30. Resolution of the temperature measurements $0.001{ }^{\circ} \mathrm{C}$.

Environment temperature, $\mathrm{T}_{\text {env, }}$, was measured with a Quat thermometer, resolution $0.01^{\circ} \mathrm{C}$.

The oil flow pressure $\mathrm{p}$ was measured at the motor inlet and outlet and at pump inlet and outlet respectively by use of Kistler piezore-

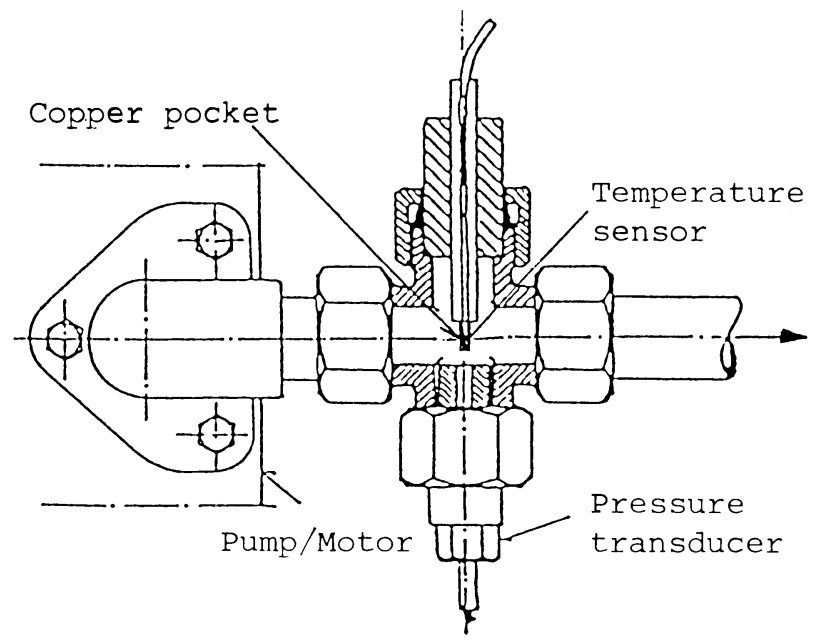

Fig.2. Installation of the temperature sensor pocket in the pipeline to and from the motor, to and from the pump.

sistive pressure sensor.

The inlet flow rate $Q_{M}$ to the motor and outlet flow rate $Q_{P}$ from the pump were both measured by a turbine flow meter located in each of the respective lines.

The rotating speed $n$ was detected as pulses from an electromagnetic pulse generator fastened to the shaft of the transmission.

Heat exchangers and a controller unit in the hydraulic circuit served to keep the oil temp- 
erature at motor inlet and at pump inlet constant in each test point. The ventilation system was accordingly controlled to keep the temperature constant in the environment.

The oil used in the hydraulic system was TELLUS 37 which is a normal mineral oil for hydraulic systems. The data of this oil at temperature $\mathrm{t}=20^{\circ} \mathrm{C}$ and atmospheric pressure are: density $\varrho=873 \mathrm{~kg} / \mathrm{m}^{3}$, specific heat capacity $c_{\mathrm{P}}=1905 \mathrm{~J} / \mathrm{kg} \mathrm{K}$ and viscosity $v=96 \mathrm{cSt}$.

\section{EXPERIMENTS}

The purpose of the experiments was to test out the agreement or differences between the two methods, the hydraulic and the thermodynamic, for determination of the efficiencies of the hydraulic transmissions.

\section{Testprogram}

Transmission I: The following operation conditions were tested

- rotating speed $n=400,800,1200$ and 1800 RPM

- pressures across

- pump $\Delta \mathrm{p}_{\mathrm{p}}=60,85,120,155$ and $190 \mathrm{bar}$

- motor $\Delta \mathrm{p}_{\mathrm{M}}=23,34,45,58$ and 68 bar

- temperatures: $\mathrm{T}_{\text {oil }}=32{ }^{\circ} \mathrm{C}$ and $46{ }^{\circ} \mathrm{C}$

Total number of tests 120 .

$$
\mathrm{T}_{\text {env. }}=15^{\circ} \mathrm{C}, 35^{\circ} \mathrm{C} \text { and } 46^{\circ} \mathrm{C}
$$

Transmission II: Operating conditions being tested:

- rotating speed $n=600,900$ and $1200 R P M$

- pressures across

- pump $\Delta \mathrm{p}_{\mathrm{P}}=40,50,60$ and 70 bar

- motor $\Delta \mathrm{p}_{\mathrm{M}}=170,210,250$ and 290 bar

- temperatures: $\mathrm{T}_{\text {oil }}=31{ }^{\circ} \mathrm{C}$ and $41^{\circ} \mathrm{C}$

Total number of tests 24 .

$$
\mathrm{T}_{\text {env. }}=25^{\circ} \mathrm{C}
$$

\section{TRANSMISSION EFFICIENCIES $\eta_{\text {hyd }}$ AND $\eta_{\mathrm{Th}}$}

The test data were worked out according to the following statements.
- The motor of both transmissions have external leakage drain. This drain was connected to the main return pipe and the leakage flow thoroughly mixed with the main flow at a safe distance upstream of the temperature sensor at the motor outlet. The leakage drain pipe was properly insulated so that no separate measurements of the leakage flow was needed.

- The thermodynamic measurements were consecutively treated according to the theory outlined in [1] and [2]. The related temperature coefficient $\mathrm{k}_{\mathrm{C}}=0.002395$.

From the thermodynamic measurements the pump efficiency $\eta_{\mathrm{thP}}$ and the motor efficiency $\eta_{t h M}$ were evaluated. The total efficiency of the transmission was then determined by

$$
\eta_{T h}=\eta_{t h P} \eta_{t h M}
$$

The recorded data from the hydraulic measurements were worked out as total efficiency of the transmission:

$$
\eta_{\text {hyd }}=\frac{Q_{P} \Delta p_{P}}{Q_{M} \Delta p_{M}}
$$

On the basis of the efficiencies according to eqs. (4.1) and (4.2) the efficiency deviation $\Delta \eta$ was determined

$$
\Delta \eta=\eta_{T h}-\eta_{h y d}
$$

For the further analysis it has been convenient to introduce the following relative quantities: Relative rotating speed $\bar{n}=n / n_{\max }$, relative pressure $\overline{\mathrm{p}}=\Delta \mathrm{p}_{\mathrm{P}} / \Delta \mathrm{p}_{\mathrm{P}_{\max }} \approx \Delta \mathrm{p}_{\mathrm{M}} / \Delta \mathrm{p}_{\mathrm{M} \max \text {. }}$ and relative power $\overline{\mathrm{P}}=\mathrm{P} / \mathrm{P}_{\max }$.

\section{RESULTS}

Transmission I: Evaluated test data results of $\eta_{\text {hyd }}$ and $\Delta \eta$ are presented in table 1 for selected powers corresponding to points numbered 1-4 on fig. 3 .

Transmission II: Results of $\eta_{\text {hyd. }}$ and $\Delta \eta$ are presented in table 2 for selected powers as indicated by numbers $1-4^{*}$ in fig. 3 . 
TABLE 1.

Test results from transmission $\mathrm{I}$.

\begin{tabular}{|c|c|c|c|c|c|c|c|c|c|c|}
\hline \multicolumn{2}{|c|}{ Nominal data } & \multicolumn{9}{|c|}{$\begin{aligned} \text { Rotating } & \text { speed } \mathrm{n}_{\max }=1800 \mathrm{RPM} \\
\text { Pump: } \mathrm{Q}_{\mathrm{P}_{\max }} & =29 \mathrm{l} / \mathrm{min}, \Delta \mathrm{p}_{\mathrm{P}_{\max }}=190 \mathrm{bar} \\
\text { Motor: } \mathrm{Q}_{\mathrm{M} \max } & =100 \mathrm{l} / \mathrm{min}, \Delta \mathrm{p}_{\mathrm{M} \max }=68 \mathrm{bar}\end{aligned}$} \\
\hline \multicolumn{2}{|c|}{$\begin{array}{l}\text { Ref. fig. } 3 \\
\text { Point no. }\end{array}$} & \multicolumn{2}{|c|}{1} & \multicolumn{2}{|c|}{2} & \multicolumn{2}{|c|}{3} & \multicolumn{2}{|c|}{4} & \multirow{5}{*}{$\begin{array}{l}\text { Best curve } \\
\text { fit to test } \\
\text { points } \Delta \eta= \\
\text { const. } / \bar{p}+K\end{array}$} \\
\hline \multicolumn{2}{|c|}{$\bar{n}=n / n_{\max }$} & \multicolumn{2}{|c|}{0.44} & \multicolumn{2}{|c|}{0.64} & \multicolumn{2}{|c|}{0.84} & \multicolumn{2}{|c|}{1.0} & \\
\hline \multicolumn{2}{|c|}{$\bar{p}=\Delta p / \Delta p_{\max }$} & \multicolumn{2}{|c|}{0.30} & \multicolumn{2}{|c|}{0.55} & \multicolumn{2}{|c|}{0.78} & \multicolumn{2}{|c|}{1.0} & \\
\hline \multicolumn{2}{|c|}{$\overline{\mathrm{P}}=\mathrm{P} / \mathrm{P}_{\max }$} & \multicolumn{2}{|c|}{0.13} & \multicolumn{2}{|c|}{0.35} & \multicolumn{2}{|c|}{0.65} & \multicolumn{2}{|c|}{1.0} & \\
\hline \multirow{5}{*}{$\begin{array}{l}\mathrm{T}_{\text {oil }}= \\
32^{\circ} \mathrm{C}\end{array}$} & $\eta_{\text {hyd }}$ & \multicolumn{2}{|c|}{0.6905} & \multicolumn{2}{|c|}{0.7572} & \multicolumn{2}{|c|}{0.7796} & \multicolumn{2}{|c|}{0,7940} & \\
\hline & $\begin{array}{l}\Delta \mathrm{t} \\
{ }^{\circ} \mathrm{C} \\
\end{array}$ & $\begin{array}{c}\Delta \eta \\
\%\end{array}$ & $\begin{array}{l}\mathrm{K} \\
\% \\
\end{array}$ & $\begin{array}{c}\Delta \eta \\
\%\end{array}$ & $\begin{array}{l}\mathrm{K} \\
\% \\
\end{array}$ & $\begin{array}{c}\Delta \eta \\
\%\end{array}$ & $\begin{array}{l}\mathrm{K} \\
\% \\
\end{array}$ & $\begin{array}{c}\Delta \eta \\
\%\end{array}$ & $\begin{array}{l}\mathrm{K} \\
\% \\
\end{array}$ & Const. \\
\hline & 17 & 9.8 & 2.7 & 4.0 & 0.4 & 1.3 & -1.8 & 0.5 & -3.9 & 2.0 \\
\hline & -3 & -1.1 & 5.6 & -0.5 & 3.1 & -1.0 & 1.4 & -1.5 & 0.5 & -2.0 \\
\hline & -18 & -3.7 & 3.0 & -2.5 & 1.1 & -3.0 & -0.4 & -3.6 & -1.6 & -2.0 \\
\hline \multirow{5}{*}{$\begin{array}{l}\mathrm{T}_{\mathrm{oil}}= \\
46^{\circ} \mathrm{C}\end{array}$} & $\eta_{\text {hyd. }}$ & \multicolumn{2}{|c|}{0.7144} & \multicolumn{2}{|c|}{0.7585} & \multicolumn{2}{|c|}{0.7835} & \multicolumn{2}{|c|}{0.7923} & \\
\hline & $\begin{array}{l}\Delta \mathrm{t} \\
{ }^{\circ} \mathrm{C}\end{array}$ & $\begin{array}{c}\Delta \eta \\
\%\end{array}$ & $\begin{array}{l}\mathrm{K} \\
\%\end{array}$ & $\begin{array}{c}\Delta \eta \\
\%\end{array}$ & $\begin{array}{l}\mathrm{K} \\
\%\end{array}$ & $\begin{array}{c}\Delta \eta \\
\%\end{array}$ & $\begin{array}{l}\mathrm{K} \\
\%\end{array}$ & $\begin{array}{c}\Delta \eta \\
\%\end{array}$ & $\begin{array}{l}\mathrm{K} \\
\%\end{array}$ & Const. \\
\hline & 22 & 10 & 2.9 & 5.0 & 1.4 & 1.0 & -1.6 & -1.2 & -3.2 & 2.0 \\
\hline & 11 & 6.5 & 0.2 & 0.6 & -3.0 & -2.2 & -4.6 & -3.5 & -5.5 & 2.0 \\
\hline & -4 & -4.5 & 2.0 & -2.6 & 1.0 & -3.3 & -0.7 & -4.5 & -2.5 & -2.0 \\
\hline
\end{tabular}

\section{DISCUSSIONS}

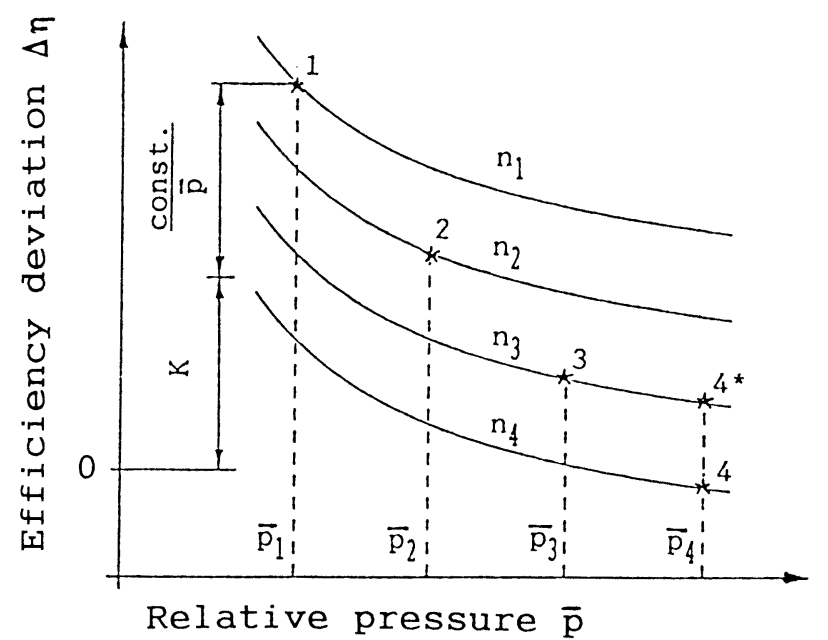

Figure 3. Efficiency deviation $\Delta \eta=\mathrm{f}(\overline{\mathrm{n}}, \overline{\mathrm{p}})$.

Result data in table 1 of the points $1-4$ and table 2 of the points $1-4^{*}$.
The referred efficiency differencies $\Delta \eta$ are those evaluated for the selected powers numbered 1-4 fig. 3, for transmission I and numbered $1-4^{*}$ for transmission II. The right column in the respective tables 1 and 2 indicate that the $\Delta \eta=\mathrm{f}(\overline{\mathrm{p}})$ for the test points of respective $n=$ const. are grouping around fitted hyperbola curves with a max. scatter of $\pm 1 \%$ for transmission I and max. scatter of $\pm 0.4 \%$ for transmission II.

The reason for fitting hyperbola curves to the $\Delta \eta$-points from the tests is based on the following hypothesis. The power heat exchange between the surfaces of the units and the surroundings may be expressed as

$$
P_{\text {heat }}=U A\left(T_{\text {oil }}-T_{\text {env }}\right)=U A \Delta t
$$

where $\quad U=$ the over all heat transfer coeff.

$A=$ area of the unit surfaces.

$$
\Delta \mathrm{t}=\mathrm{T}_{\text {oil }}-\mathrm{T}_{\text {env }} \text {. }
$$


TABLE 2.

Test results from transmission II.

\begin{tabular}{|c|c|c|c|c|c|c|c|c|c|c|}
\hline \multicolumn{2}{|c|}{ Nominal data } & \multicolumn{9}{|c|}{$\begin{array}{l}\text { Rotating speed } \mathrm{n}_{\max }=1200 \mathrm{RPM} \\
\text { Pump: } \mathrm{Q}_{\mathrm{P}_{\max }}=80 \mathrm{l} / \mathrm{min}, \Delta \mathrm{p}_{\mathrm{P}_{\max }}=70 \mathrm{bar} \\
\text { Motor: } \mathrm{Q}_{\mathrm{M} \max }=24 \mathrm{l} / \mathrm{min}, \Delta \mathrm{p}_{\mathrm{M} \max }=290 \mathrm{bar}\end{array}$} \\
\hline \multicolumn{2}{|c|}{$\begin{array}{l}\text { Ref. fig. } 3 \\
\text { Point no. }\end{array}$} & \multicolumn{2}{|c|}{1} & \multicolumn{2}{|c|}{2} & \multicolumn{2}{|c|}{3} & \multicolumn{2}{|c|}{$4^{*}$} & \multirow{5}{*}{$\begin{array}{l}\text { Best curve } \\
\text { fit to test } \\
\text { points } \Delta \eta= \\
\text { const. } / \bar{p}+K\end{array}$} \\
\hline \multicolumn{2}{|c|}{$\overline{\mathrm{n}}=\mathrm{n} / \mathrm{n}_{\max }$} & \multicolumn{2}{|c|}{0.5} & \multicolumn{2}{|c|}{0.75} & \multicolumn{2}{|c|}{1.0} & \multicolumn{2}{|c|}{1.0} & \\
\hline \multicolumn{2}{|c|}{$\bar{p}=\Delta p / \Delta p_{\max }$} & \multicolumn{2}{|c|}{0.57} & \multicolumn{2}{|c|}{0.72} & \multicolumn{2}{|c|}{0.85} & \multicolumn{2}{|c|}{1.0} & \\
\hline \multicolumn{2}{|c|}{$\overline{\mathrm{P}}=\mathrm{P} / \mathrm{P}_{\max }$} & \multicolumn{2}{|c|}{0.285} & \multicolumn{2}{|c|}{0.54} & \multicolumn{2}{|c|}{0.85} & \multicolumn{2}{|c|}{1.0} & \\
\hline \multirow{3}{*}{$\begin{array}{l}\mathrm{T}_{\mathrm{ou}}= \\
31^{\circ} \mathrm{C}\end{array}$} & $\eta_{\text {hyd }}$ & \multicolumn{2}{|c|}{0.8124} & \multicolumn{2}{|c|}{0.8387} & \multicolumn{2}{|c|}{0.8303} & \multicolumn{2}{|c|}{0,8375} & \\
\hline & $\begin{array}{l}\Delta \mathrm{t} \\
{ }^{\circ} \mathrm{C}\end{array}$ & $\begin{array}{c}\Delta \eta \\
\%\end{array}$ & $\begin{array}{l}\mathrm{K} \\
\% \\
\end{array}$ & $\begin{array}{c}\Delta \eta \\
\%\end{array}$ & $\begin{array}{l}\mathrm{K} \\
\%\end{array}$ & $\begin{array}{c}\Delta \eta \\
\%\end{array}$ & $\begin{array}{l}\mathrm{K} \\
\%\end{array}$ & $\begin{array}{c}\Delta \eta \\
\%\end{array}$ & $\begin{array}{l}\mathrm{K} \\
\%\end{array}$ & Const. \\
\hline & $6^{\circ} \mathrm{C}$ & 2.3 & -1.2 & -0.3 & -3.0 & -1.0 & -3.3 & -1.3 & -3.3 & 2.0 \\
\hline \multirow{3}{*}{$\begin{array}{l}\mathrm{T}_{\mathrm{oul}}= \\
41^{\circ} \mathrm{C}\end{array}$} & $\eta_{\text {hyd }}$ & \multicolumn{2}{|c|}{0.7630} & \multicolumn{2}{|c|}{0.7950} & \multicolumn{2}{|c|}{0.7876} & \multicolumn{2}{|c|}{0.7977} & \\
\hline & $\begin{array}{l}\Delta \mathrm{t} \\
{ }^{\circ} \mathrm{C} \\
\end{array}$ & $\begin{array}{c}\Delta \eta \\
\% \\
\end{array}$ & $\begin{array}{l}\mathrm{K} \\
\% \\
\end{array}$ & $\begin{array}{c}\Delta \eta \\
\%\end{array}$ & $\begin{array}{l}\mathrm{K} \\
\% \\
\end{array}$ & $\begin{array}{c}\Delta \eta \\
\%\end{array}$ & $\begin{array}{l}\mathrm{K} \\
\% \\
\end{array}$ & $\begin{array}{c}\Delta \eta \\
\% \\
\end{array}$ & $\begin{array}{l}\mathrm{K} \\
\%\end{array}$ & Const. \\
\hline & $16^{\circ} \mathrm{C}$ & 4.3 & 0.8 & 1.8 & -1.0 & 1.0 & -1.3 & 0.7 & -1.3 & 2.0 \\
\hline
\end{tabular}

This heat flow originates from the oil flow through the units and is propotional to $\Delta \mathrm{t}$. For $\Delta t>0$ this means a corresponding increase of the thermodynamic efficiency for the pump as well as for the motor. Another effect, however small, in the opposite way is the thermodynamic process in the units which cause a change of the temperature in the oil flow.

Further it is reasonable to consider the power of the heat flow as approximately const. for $\Delta \mathrm{t}=$ const. Comparing this statement with the transmission power

$P=$ const. $n \Delta p$

then $\Delta \eta \sim \frac{P_{\text {heat }}}{P}=\frac{\text { Const. }}{\bar{n} \bar{p}}$

For $\Delta \mathrm{t}=$ const. this means that

$\left.\left.\Delta \eta\right|_{\bar{p}} \sim \frac{K_{n}}{\bar{n}}\right|_{\bar{p}}$ and $\left.\Delta \eta\right|_{\bar{n}} \sim \frac{K_{p}}{\bar{p}}$

which describe hyperbola curves for $\left.\Delta \eta\right|_{\bar{n}}=f(\bar{p})$ and $\left.\Delta \eta\right|_{\bar{p}}=f(\bar{n})$

respectively. On this basis the deviations $\Delta \eta$ may be described by the following equation

$$
\Delta \eta=K_{n}\left(\frac{1}{n}-1\right)+K_{p}\left(\frac{1}{\bar{p}}-1\right)+K_{t} \Delta t+C
$$

Adjusted values of the constants/coefficients in eq. (6.5) to fit $\Delta \eta$ of the transmissions being reported, are given in table 3 for $0.5 \leq \mathrm{n} / \mathrm{n}_{\max } \leq 1.0$ and $0.5 \leq \Delta \mathrm{p} / \Delta \mathrm{p}_{\max } \leq 1.0$.

A diagram of $\Delta \eta$ with the constants of transmission II and $\Delta t=0$ is shown on fig. 4 .

As supposed at start the correct total efficiency of the transmission

$$
\eta_{\text {tot }}=\eta_{h y d}=\eta_{T h}-\Delta \eta
$$

By inserting the constants from table 3 in eq. (6.5) and combining with eq. (6.6) the corrected $\eta_{\mathrm{Th}}$-values coincide with the $\eta_{\text {hyd. }}$ within a tolerance of $\pm 1 \%$ for transmission I and a tolerance $\pm 0.5 \%$ for transmission II.

It is however clear that the coincidence of the results of these two methods would improve considerably by higher pressure differences $\Delta p$ across the units. May be it should be at least $\Delta p>100$ bar. 
TABLE 3

Coefficients of eq. (6.5)

\begin{tabular}{|c|c|c|c|c|c|}
\hline \multicolumn{2}{|c|}{ Transmission } & $\mathrm{K}_{\mathrm{n}}$ & $\mathrm{K}_{\mathrm{p}}$ & $\mathrm{K}_{\mathrm{t}}$ & $\mathrm{C}$ \\
\hline \multirow{2}{*}{ I } & $\mathrm{T}_{\mathrm{oil}}=32^{\circ} \mathrm{C}$ & 0.0375 & 0.02 & 0.0012 & -0.014 \\
\hline & $\mathrm{T}_{\mathrm{oil}}=46^{\circ} \mathrm{C}$ & 0.0375 & 0.02 & 0.0013 & -0.04 \\
\hline II & $\begin{array}{l}\mathrm{T}_{\text {oil }}=31^{\circ} \mathrm{C} \\
\text { and } 41^{\circ} \mathrm{C}\end{array}$ & 0.026 & 0.02 & 0.002 & -0.028 \\
\hline
\end{tabular}

\section{CONCLUSIONS}

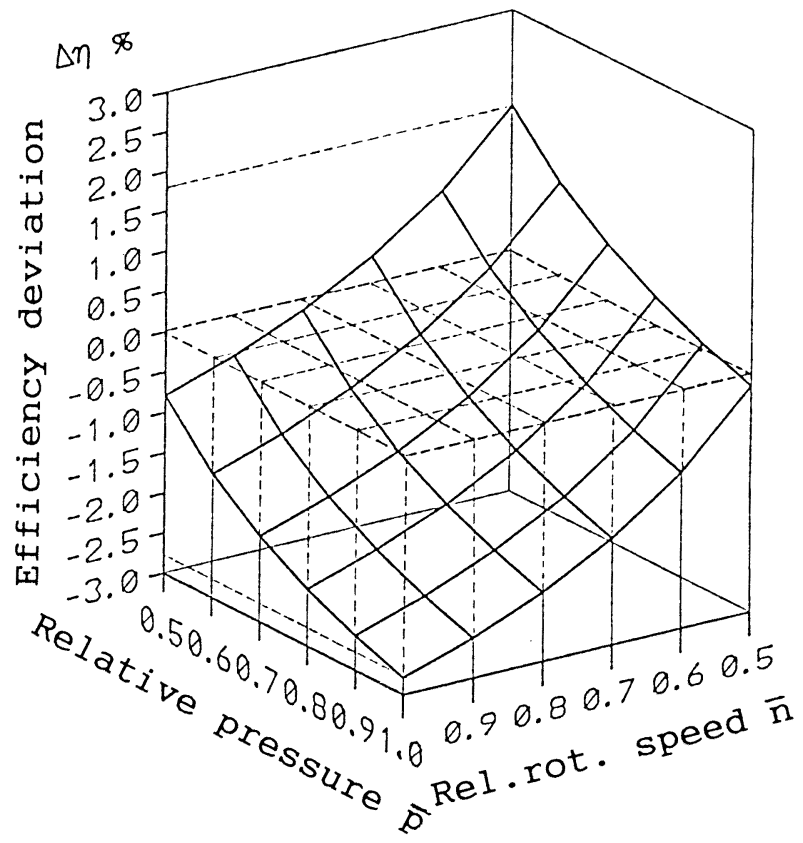

Fig. 4. Deviation $\Delta \eta=f(\bar{n}, \bar{p})=2.6 / \bar{n}+2 / \bar{p}-7.4$ for $\Delta \mathrm{t}=0$.
Tests of two different hydraulic transmissions show agreement within $\pm 3 \%$ between thermodynamic measurements and hydraulic measurements of the efficiency within the ranges $0.5 \leq \mathrm{n} / \mathrm{n}_{\max }<1.0$ and $0.5 \leq \Delta \mathrm{p} / \Delta \mathrm{p}_{\max }<1.0$ when temperature difference $\mathrm{T}_{\text {oil }}-\mathrm{T}_{\text {env. }}=0$.

A proposed analytic equation for correction of the thermodynamic efficiency has been qualitatively proved and indicate that the deviations between the thermodynamic and hydraulic measurements of the efficiency may be reduced to $0.5 \%-1.0 \%$ within the referred ranges of rotating speeds and pressures.

Higher pressures across the motor and the pump respectively would have reduced the deviations even better.

These tests have proved the applicability of the thermodynamic method on hydraulic units for steady state conditions. However, further investigations are needed for determination of the limitations.

\section{REFERENCES}

[1] Kjølle, A. "Thermodynamic Methods for Determining Losses in Hydraulic Components-A survey", NEL Report No. 657, East Kilbride, Glasgow: National Engineering Laboratory, 1978.

[2] Kjølle, A. "Relationship of pvT Conditions and $c_{p}$ of Oils for Thermodynamic Measurements", NEL Report No. 658, East Kilbride, Glasgow: National Engineering Laboratory, 1978.

[3] Kjølle, A. " Test Results of a Hydraulic Transmission", 15th Meeting of GPMT at Bergen, 11.14. June 1990.

[4] Witt, K. "Druckflüssigkeiten und thermodynamisches Messen", Ingenieur Digest Verlagsgesellshaft GmbH, Frankfurt/Main, 1974. 